\title{
Elaboración de una guía visual sobre experiencias en materia de conservación de colecciones en archivos y bibliotecas
}

\author{
Leticia Paula Dobrecky \\ Centro de Documentación e Información Agropecuaria - Argentina.
}

ARTÍCULO / ARTICLE

\begin{abstract}
Resumen
Se presenta una propuesta para reunir imágenes sobre experiencias llevadas a cabo por archivos y bibliotecas en materia de conservación de colecciones que se encuentran disponibles en los sitios web de las instituciones. Para tal fin, se diseña una guía orientada a la identificación visual de las problemáticas relacionadas con dicha temática. Para ello, se inicia con la búsqueda y descripción de los materiales seleccionados hasta la difusión y publicación de la obra en el repositorio E-LIS. El análisis de los resultados permite establecer que si bien una de sus principales ventajas es la facilidad de consulta, aún falta incorporar mayor funcionalidad para la recuperación de la información. Se está comenzando a desarrollar un nuevo recurso en un entorno más dinámico para superar dicha limitación.
\end{abstract}

Palabras clave

Conservación ; Colecciones ; Archivos ; Bibliotecas ; Factores de deterioro ; Base de conocimiento ; Buenas prácticas

\section{Design of a visual guide about collections conservation experiences in archives and libraries}

\section{Abstract}

This article presents a way to gather images about experiences on collection conservation in archives and libraries that are published on Internet. For that purpose, a guide about visual identification of deterioration or good practices is designed. In this way, several steps are followed: search, selection, description of materials up to the promotion and publication of such work on the E-LIS repository. The analysis of the results showed that is necessary to improve the way in which the information is retrieved. Based on this, a new tool will be developed in a more dynamic environment.

Keywords

Conservation ; Collections ; Archives ; Libraries ; Knowledge database ; Deterioration factors ; Good practices

\section{Introducción}

Conservar, preservar, restaurar. Como establece Hilda Léon Castellanos (2001) existe en este campo una pluralidad conceptual que ha llevado a la asimilación de diferentes términos. Las divergencias en cuanto al nombre genérico de la disciplina tienen dos tendencias en las que los usos idiomáticos han desempeñado su papel. Algunos científicos son partidarios del vocablo conservación, mientras que otros prefieren preservación. Justamente, la autora explica que en sus inicios, el propósito fundamental de la disciplina era mantener y restaurar. En la actualidad, una de las corrientes distingue dos disciplinas y dos especialidades profesionales para su ejercicio: Preservación y Conservación. La otra plantea la existencia de una sola disciplina, la Conservación, que posee dos vías de actuación: la Preservación o Conservación Preventiva y la Restauración (p. 26). 
El Consejo Internacional de Museos (ICOM-CC por sus siglas en idioma inglés: International Council of MuseumsCommittee for Conservation) plantea la necesidad de una terminología clara y coherente, que facilite la comunicación entres sus miembros, entre la comunidad de profesionales del patrimonio a nivel mundial, y con el público en general. De ahí, que durante la Conferencia Trienal desarrollada en el año 2008 en Nueva Delhi plantearon las definiciones de la conservación como la disciplina que abarca a la conservación preventiva, la curativa y la restauración. Además, especifica que los términos se distinguen entre sí porque las medidas y acciones de cada una de ellas presentan diferentes objetivos. (ICOM-CC, 2008).

Más allá de la diversidad de términos, existe una preocupación en todas las instituciones que está dada por los peligros reales y potenciales a los que se exponen los materiales tanto por causas endógenas como exógenas. Justamente, Sherelyn Ogden (1998) plantea que tanto las bibliotecas como los archivos se encuentran amenazados por un problema masivo de deterioro y pérdida de sus colecciones. Muchas son cada vez más frágiles y algunas de ellas corren el riesgo de perderse para siempre. El tiempo transcurrido entre la generación del documento y su completa destrucción (ciclo de vida), depende en buena medida de las acciones de prevención acometidas en las organizaciones de información. (León Castellanos, 2001).

Fuensanta Salvador López (2003), establece que las medidas previsoras siempre se aplican al medio y, a pesar de que algunas pueden ser costosas, su adopción es mucho más rentable y eficaz que permanecer impasible o confiar en la eficacia de la restauración, que actúa individual y directamente sobre la pieza, y que es mucho más costosa y arriesgada, y sobre todo, nunca puede devolver la integridad ya perdida. Justamente, siguiendo esta línea de pensamiento, Vaillant y Valentín (citado en León Castellanos, 2001) definen a la conservación preventiva como cualquier medida encaminada a evitar o reducir el potencial de daños y se fundamenta en el cuidado de las colecciones más que en el tratamiento individual de los documentos.

Ahora bien, ¿en qué consisten las acciones preventivas? Arsenio Sánchez Hernampérez (1998), menciona cinco materias relacionadas con dicha labor: el control de los factores ambientales (humedad, temperatura, calor, contaminantes atmosféricos, microorganismos e insectos); la valoración de las características del edificio para detectar y corregir los problemas estructurales; la planificación de siniestros; las actividades relacionadas con la protección y mantenimiento de los materiales. Finalmente, para lograr una adecuada manipulación de los fondos, la educación de los trabajadores y de los usuarios. Además, se incluyen las políticas, el desarrollo de guías, directrices y procedimiento para proteger las colecciones. (León Castellanos, 2001).

Un aspecto importante es la responsabilidad de las tareas de conservación que le compete a todos. Mientras que los especialistas en preservación y conservación pueden aconsejar y llevar a cabo las actividades específicas, es tarea de todo el personal de la biblioteca, desde el director hacia abajo, salvaguardar las colecciones. Las medidas deben ser respaldadas, apoyadas e incentivadas por todo el personal de la biblioteca, cualquiera sea su nivel. (IFLA, 2000). Además se debe formar a los usuarios para evitar y prevenir los daños que se producen debido a la manipulación descuidada y la consulta frecuente (Salvador López, 2003).

Muchas bibliotecas y/o archivos difunden en sus respectivos sitios webs las tareas que realizan para conservar las colecciones y cómo los usuarios pueden incorporar nuevos hábitos para contribuir a retardar los daños. En la página de la Universidad de Delaware', por ejemplo, se describen las causas del deterioro de los materiales, los daños que se pueden evitar, el rol del usuario y del personal para resguardar la colección. Por otro lado, en el State Archives of Floridaii brinda información destinada a que cada persona pueda ayudar a prolongar la vida de los libros, cds/dvds, fotografías.

Janet Gertz de la Preservation and Digital Conversion Division iii perteneciente a la Biblioteca de la Universidad de Columbia elaboró varias presentaciones sobre diferentes temáticas como ser: las causas de los deterioros, las prácticas en el manejo y almacenamiento, cómo identificar y prevenir los daños.

En el Archivo de Bogotá se elaboró un trabajo que es una introducción general acerca de cómo se pueden identificar, de manera sencilla, los deterioros que presentan los documentos que han sido producidos en soportes o papeles de tipo industrial. La idea es ofrecer información básica para facilitar a los funcionarios de la Administración Pública, que tengan bajo su custodia el patrimonio documental de los archivos de las entidades distritales, asumir una actitud responsable y de compromiso frente al cuidado de los fondos documentales. (Guerrero Mateus, s.f.) 
Hasta aquí se citaron algunos ejemplos de instituciones que brindan información sobre conservación de colecciones. Además, existen recursos especializados en esta temática que se encuadran dentro de la denominada web 2.0. Se mencionan a modo de ejemplo: el blog diseñado por el Instituto Nacional de Tecnología Industrial de la República Argentina $^{\text {iv }}$ (INTI) y la wiki de la American Institute for Conservation of Historic and Artistic Works (A.I.C.) ${ }^{v}$.

El blog del INTI- Celulosa y Papel está especializado en conservación con la idea de sumar un espacio más donde se pueda compartir información, experiencias, novedades dentro de la profesión, consejos, preguntas y debates.

El otro recurso es el Conservation Catalog del A.I.C. En este caso, la responsabilidad sobre la edición recae en un grupo de editores especializados, mientras que los usuarios registrados pueden opinar y realizar aportes desde la sección de comentarios. La idea de crear una base de conocimientos on-line en permanente actualización permitirá mejorar la calidad de los contenidos y ampliar su extensión de una manera mucho más eficaz. Al mismo tiempo, posibilitará el acceso a muchos más usuarios (Fundación Patrimonio Histórico, 2009).

Más allá del gran caudal de bibliografía en torno a la conservación de las colecciones, se quiere destacar el importante rol que juegan los archivos y bibliotecas al publicar en sus sitios webs sus experiencias en torno a dicha materia. No sólo ayudan a formar a usuarios y a los profesionales que se desempeñan en las instituciones sino que también brindan información textual y gráfica al documentar sus actividades con fotografías.

En base a ello, se propone diseñar una herramienta que reúna ese bagaje de experiencias llevadas a cabo por las instituciones que testimonien con imágenes su labor (esto es: deterioros existentes, soluciones, y/o buenas prácticas) y que se encuentren disponibles en Internet. Por lo tanto, el objetivo del trabajo es presentar una guía para la identificación visual de problemáticas relacionadas con la conservación de colecciones de archivos y bibliotecas. Su finalidad es que los profesionales la utilicen como una obra de consulta permanente que los oriente al momento de reconocer los deterioros reales y los peligros potenciales.

Es fundamental citar los antecedentes relacionados con esta propuesta. Por un lado, el Archives Damage Atlas. Es una traducción al inglés del Schadeatlas archieven publicado por el Netherlands' National Programme for the Preservation of Papel Heritage (Metamorfoze) en el año 2007. El propósito de esta herramienta es ayudar a identificar los daños y señalar sus causas, además de ser el primer escalón para establecer un plan de preservación (Metamorfoze, 2010). Su originalidad está dada en su contenido que está centrado en imágenes.

El segundo caso se dio en el año 2011 cuando se empezó a desarrollar una base de conocimiento sobre conservación. Se utilizó el software Winlsis para presentar el modelo de base de datos. El énfasis estaba dado en la recuperación de las imágenes en función de las problemáticas o de las soluciones planteadas por los autores de los trabajos (Dobrecky, 2011).

Cabe destacar que la idea de una "guía visual" se toma de la obra realizada por el Instituto Nacional de Tecnología Agropecuaria de la República Argentina (INTA) para el diagnóstico visual de eficacia en cancrosis de los citrus. El propósito de la guía fue facilitar, principalmente, a la actividad privada, el reconocimiento de los síntomas de dicha enfermedad y así evitar su traslado a través de la comercialización desde los establecimientos citrícolas afectados. La variedad de síntomas y la forma en que se presentan las frutas que están a la venta originaron las numerosas fotografías que se obtuvieron. (Messina, 2010).

\section{Materiales y metodología}

Como en muchos otros ámbitos del quehacer humano, la ciencia política y la práctica de gobierno no han logrado el establecimiento de un cuerpo teórico consensuado que de sustento a la actividad cotidiana de gobernar. Uno de los temas relevantes de la ciencia política, por el carácter aplicativo que debe tener, es el de las políticas públicas, sobre el cual se han formulado en las décadas recientes definiciones que han venido a dilucidar bastante el concepto, pero que todavía no han conseguido convencer a todos los involucrados, mucho menos lograr que sobre esa certeza, normen su desempeño como servidores públicos. 
A continuación se describen cada una de las fases que fueron necesarias para desarrollar la Guía.

\section{Fase 1: Búsqueda y selección de experiencias}

En primer lugar, se realiza una búsqueda general en Internet para conocer la cantidad aproximada de programas, proyectos, planes y buenas prácticas llevados a cabo por bibliotecas y/o archivos sobre conservación. A partir de allí, se procede a revisar los documentos para detectar cuáles de ellos contienen imágenes que den cuenta de las actividades descriptas.

\section{Fase 2: Almacenamiento y descripción de los trabajos seleccionados}

En segundo lugar, se describen aquellos documentos que contengan imágenes. Para ello, se desarrolla una base de datos en Winlsis cuya función es utilizarla como un instrumento de registro de los materiales seleccionados y de acceso a los mismos de forma rápida. Se opta por dicho programa por su gratuidad y sencillez.

Se establece que los campos que van a componer los registros de la base de datos serán: Problemáticas, Descripción, Medidas, Descripción-medidas, Recomendaciones, Descripción-recomendaciones, Notas, Palabras claves, Fuente, Disponibilidad y Referencias. Cabe destacar que se incluyen hipervínculos en los campos Problemáticas, Medidas, Recomendaciones, Disponibilidad y Referencias (Del mismo/a autor/a). En el caso de los tres primeros, se vincula con la imagen.

Luego, se analiza qué es lo que se va a indizar. Se decide que sólo el campo de Palabras Claves se va a enviar al diccionario ya que lo que interesa conocer es cuál es la problemática o la solución y así vincularlo con la fuente correspondiente.

Se siguen los pasos del asistente para la creación de la Tabla de Definición de campos (se incluyen los mencionados anteriormente), luego se seleccionan los que van a componer la planilla de ingreso de datos (en este caso todos los campos), se elige el formato decorado, y se selecciona "Palabras Claves" para el diccionario utilizando la técnica 2. Una vez finalizado el proceso, se realizan las modificaciones pertinentes en la tabla de extracción de datos (FST) y se incorporan los enlaces al formato de impresión.

Antes de comenzar con el paso siguiente, es decir, la carga de los documentos en la base de datos, se elabora un listado de palabras claves extraídas de esos mismos materiales basándose en el lenguaje natural con un mínimo de control para evitar tanto ruido en la recuperación de la información.

\section{Fase 3: Carga en la Base de datos}

Para el ingreso de los documentos en la base de datos se sigue el criterio siguiente: se generan registros en función de la problemática, de las medidas o las recomendaciones analizadas por los autores. Esto significa que se describen cada uno por separado, salvo que se presenten el problema junto con la solución. Se van a vincular entre ellos por el número de registro en el campo "Del mismo/a autor/a".

Las imágenes que se encuentran en los documentos se transforman en JPEG utilizando para ello un editor básico como el Paint. El objetivo sólo es el de unificar los formatos sin alterar las mismas. Cada una de ellas se guarda en la carpeta de Winlsis denominada bg.

Se procede al ingreso.

\section{Fase 4: Diseño de la Guía}

Una vez que se procede a la carga completa en la base de datos, se crea la Guía visual.

Para su elaboración se utilizan como materia prima los documentos ingresados en la base de datos. Las imágenes se organizan dentro de cinco apartados según la problemática analizada: factores humanos, factores biológicos, factores ambientales, catástrofes, otros factores (foxing, manchas, tintas, etc.). En cada caso se presenta una descripción de lo que se observa en la misma. Al final de cada capítulo se incluye la fuente correspondiente. Para facilitar la búsqueda se elabora un índice ${ }^{\mathrm{vi}}$. 
Fase 5: Difusión de la Guía

Se decide publicar la obra en el repositorio E-Prints in Library and Information Science (E-LIS) ya que en dicho sitio se registran las estadísticas de consulta y es un modo de medir el interés del trabajo entre los profesionales.

\section{Resultados}

A continuación, se presenta un registro extraído de la base de datos realizada en Winlsis. Como se podrá observar, no se accede directamente a la imagen (Figura 1), sino que se debe hacer un clic en el hipervínculo del campo Problemáticas (Figura 2). Lo mismo para el caso de la Disponibilidad de la fuente y para las Referencias. Es importante destacar que la forma de citación es básica ya que lo que se quiere resaltar es el autor y la dirección del sitio web. Además, sólo es un instrumento de control de la documentación seleccionada hasta el momento. Al menos, inicialmente, no está pensada como un producto para difusión masiva.

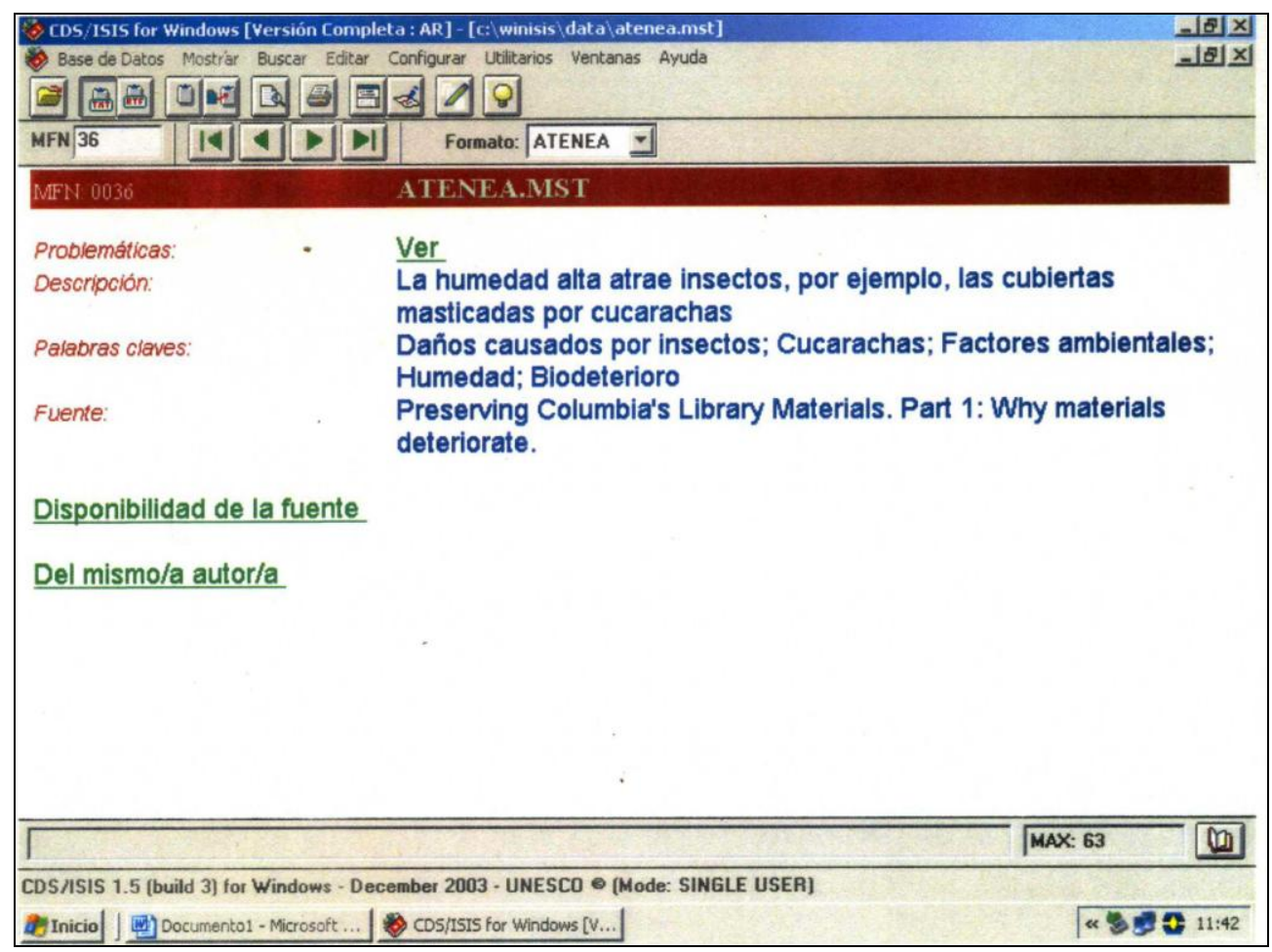

Figura 1 - Ejemplo de registro de la base de datos que se utiliza como herramienta de control 


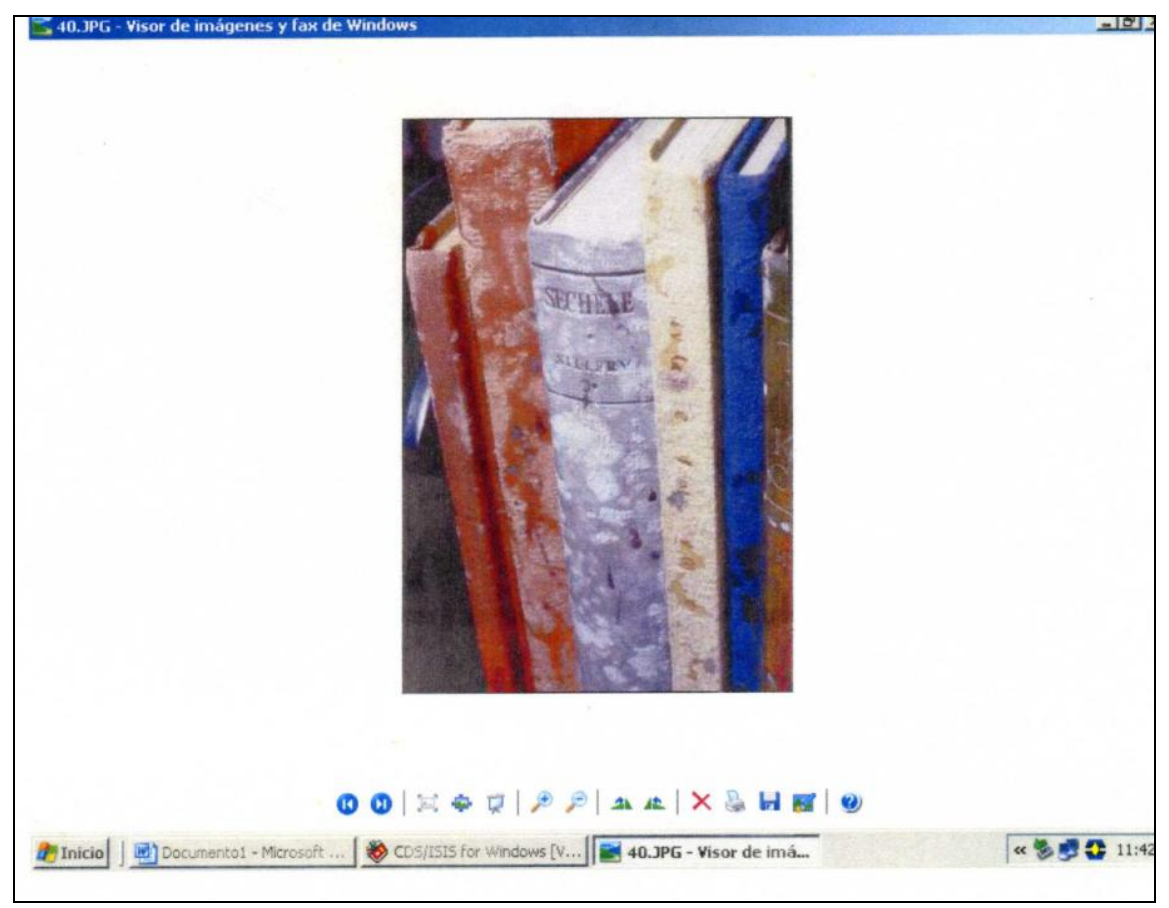

Figura 2 - Imagen a la cual se accede desde el enlace (Ver) del campo Problemáticas

Luego, se visualiza un extracto de una de las páginas de la Guía (Figura 3) en la cual se pueden consultar directamente las imágenes en función de los deterioros que presenta.

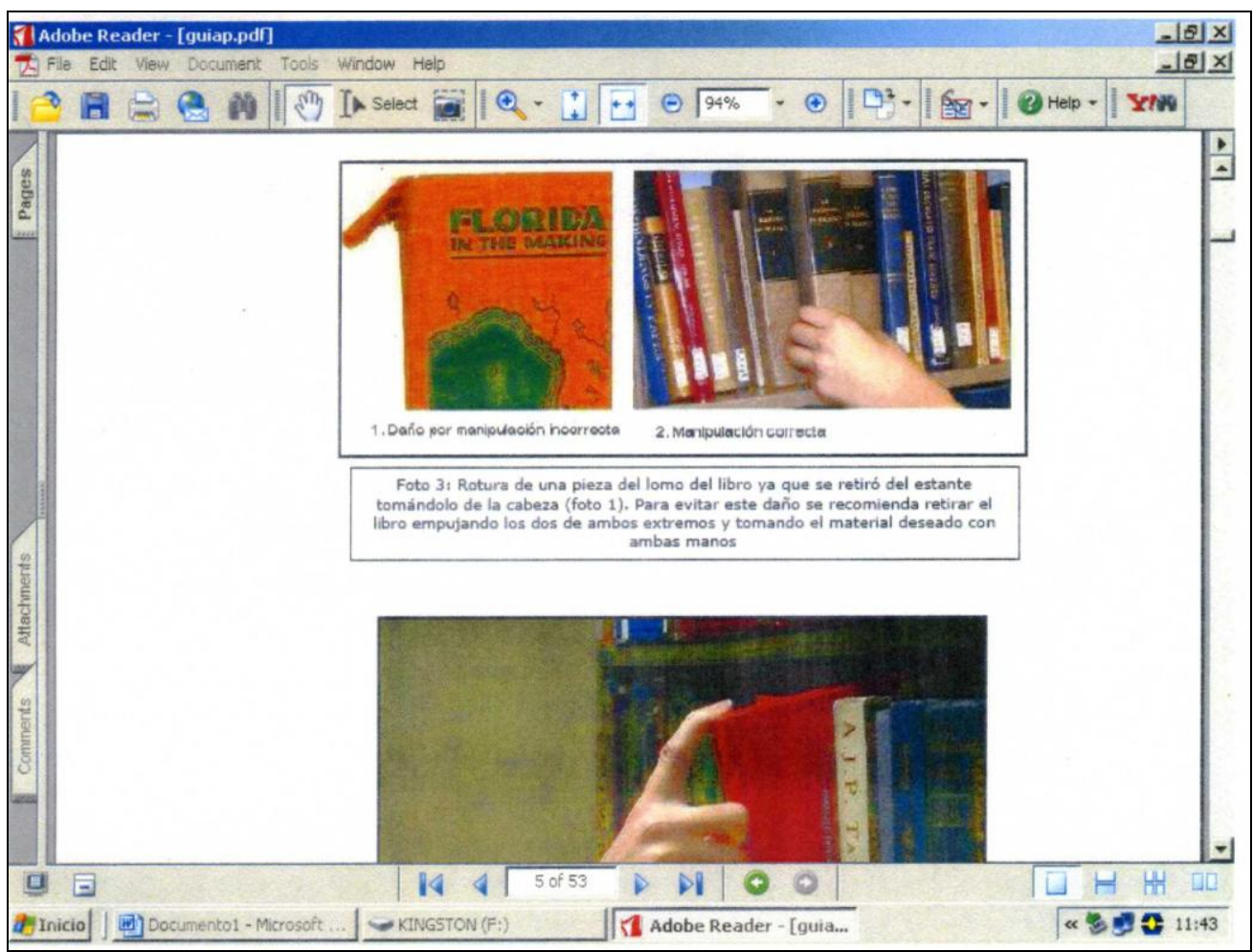

Figura 3 - Extracto de una página de la Guía 


\section{Discusión y conclusiones}

Esta primera edición de la Guía es una forma de ejemplificar con imágenes los principales conceptos analizados en las publicaciones sobre conservación.

Entre las ventajas que presenta la obra es que permite tener una visión general de los efectos de los principales agentes de deterioros sobre las colecciones. Además es de lectura ágil y fácil de consultar. Cabe destacar que también reúne y fomenta la difusión de la labor desarrollada por los profesionales, quienes vuelcan sus conocimientos en los sitios web de sus instituciones.

Existen dos limitaciones importantes a considerar: una relacionada con el contenido y la otra con su diseño. En primer lugar, se hace evidente la escasa documentación visual de los efectos de los factores biológicos sobre los materiales. En segundo lugar, como la obra fue ideada para ser impresa, no incorpora ninguna funcionalidad (por ejemplo: hipervínculos) para agilizar la búsqueda. Justamente, se está desarrollando un nuevo diseño de herramienta que incorpore las ventajas de un entorno más dinámico.

Por último, cabe agregar que se continúan buscando en Internet más experiencias documentadas con imágenes para que se cuente con un mayor caudal de conocimiento sobre la temática y se pueda utilizar dicho recurso en el trabajo cotidiano. Además, es fundamental continuar con una mayor difusión de la Guía para conocer la opinión de los profesionales sobre ella y a partir de allí incorporar mejoras continuas. 


\section{Referencias}

Adcock, E. (Ed.). (2000). IFLA: Principios para el cuidado y manejo de material de bibliotecas. Santiago de Chile: DIBAM. Recuperado de: http://ifla.queenslibrary.org/VI/4/news/pchlm-s.pdf

Consejo Internacional de Museos-ICOM-CC. (2008). Terminología para definir la conservación del patrimonio cultural tangible. Trabajo presentado en la 15a Conferencia Trianual. Nueva Delhi. Recuperado de http://www.icom-cc.org

Dobrecky, L.P. (2011). Diseño de una base de datos sobre experiencias en conservación en colecciones de archivos y bibliotecas. En: Póster presentado en la 43 ${ }^{\underline{a}}$ Reunión Nacional de Bibliotecarios. Buenos Aires. Recuperado de http://www.abgra.org.ar/43 poster.htm

Fuentes Espinoza, G. (2007). Guía de conservación preventiva de documentos en papel. Chile: Dirección de Archivos, Bibliotecas y Museos. Recuperado de http://pmgsaip.leydetransparencia.cl/?q=node/43

Fundación Patrimonio Histórico. 2009. Una wiki sobre conservación. Recuperado de: http://www.patrimoniohistorico.org.ar/novedades/110-un-wiki-sobre-conservacion.html

Guerrero Mateus, L. (s.f.). Deterioros más comunes del material de archivo. Bogotá: Archivo. Recuperado de: http://www.archivobogota.gov.co/libreria/php/decide.php?patron=01.090610

León Castellano, H.R. (2001). Problemática de la conservación preventiva en instituciones cubanas de información. Ciencias de la información, 32(3), 25-32. Recuperado de: http://cinfo.idict.cu/index.php/cinfo

Messina, M.A. (2010). Diagnóstico visual de eficacia en cancrosis de los citrus: una guía para la caracterización de los síntomas en frutas que pueden albergar la bacteria capaz de originar la enfermedad, a fin de evitar su dispersión a través de la comercialización. Buenos Aires: INTA, 2010.

Metamorfoze. (2010). Archives Damage Atlas: a tool fro assessing damage. The Hague: Metamorfoze. Recuperado de http://en.nationaalarchief.nl/newsroom/news/english-version-of-archives-damage-atlas

Ogden, S. (Ed.). (1998). Manual de Preservación de Bibliotecas y Archivos del Northeast Document Conservation Center. Santiago de Chile: DIBAM. Recuperado de http://www.nedcc.org/resources/downloads/spplam3.pdf

Salvador López, F. (2003). Políticas y planes de preservación en bibliotecas: actitudes, contenido y objetivos. Trabajo presentado en el Primer Seminario sobre Patrimonio Bibliográfico Vasco, Vitoria-Gasteiz. Recuperado de http://www.kultura.eigv.euskadi.net/r46-4874/eu/contenidos/evento/ondare mintegia/eu 12730/eu txostenak.html

Sánchez Hernampérez, A. (1999). Políticas de conservación en bibliotecas. Madrid: Arco/Libros.

\section{Notas}

i University of Delaware - http://www2.lib.udel.edu/Preservation/prevention/prevention.htm

ii Florida Department of State. Division of Library and Information Services. Disponible en: http://dlis.dos.state.fl.us/archives/preservation/index.cfm

iii Disponible en: https://library.columbia.edu/content/librarywebsecure/bts/preservation.html

${ }^{i v}$ Disponible en: http://www.conservarpapel.blogs.inti.gob.ar

${ }^{\vee}$ Disponible en: http://www.conservation-wiki.com

vi El trabajo se titula "Diagnóstico visual de problemáticas relacionadas con la conservación de colecciones de archivos y bibliotecas". Disponible en: http://eprints.rclis.org/ 


\section{Datos del autor}

\section{Leticia Paula Dobrecky}

Licenciada en Bibliotecología y Ciencia de la Información con orientación en Servicios y Recursos de Información. Facultad de Filosofía y Letras de la Universidad de Buenos Aires. Desde el 2002 al 2003 participó en un proyecto de actualización de una página web en la Cátedra de Fuentes de Información Especializada en Humanidades y Ciencias Sociales de la Facultad de Filosofía y Letras de la Universidad de Buenos Aires. Durante el 2003 trabajó en el Centro de Documentación e Información del Ministerio de Economía y Producción. Actualmente se desempeña en el Centro de Documentación e Información Agropecuaria del Ministerio de Agricultura, Ganadería y Pesca.

Idobre@minagri.gob.ar

$\begin{array}{ll}\text { Recibido-Received } & : 2012-11-04 \\ \text { Aceptado-Accepted } & : 2012-12-30\end{array}$

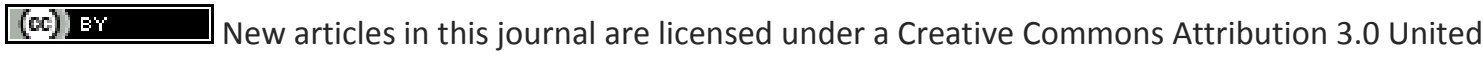
States License.

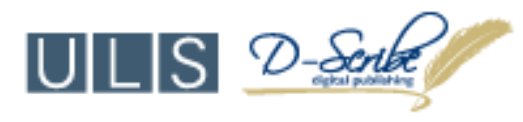

This journal is published by the University Library System of the University of Pittsburgh as part of its $\underline{D-S c r i b e}$ Digital Publishing Program and is cosponsored by the University of Pittsburgh Press. 